\title{
Molecular dynamics of the glass relaxation process of the soft phase in block copolymers: effect of molecular architecture
}

\author{
Sayed Z. Mohammady
}

Received: 30 May 2006/Accepted: 30 April 2007 / Published online: 4 June 2007

(C) Springer-Verlag 2007

\begin{abstract}
To determine the impact of molecular architecture on the molecular dynamics of the glass relaxation processes of soft blocks in different types of block copolymers, model block copolymers with a variation in both molecular architecture and chemical composition were studied. Four block copolymer models, namely, two styrene-butadiene-styrene (S-B-S) block copolymers and two styrene-styrene butadiene-styrene (S-SB-S) were chosen. In each pair of block copolymers, one is linear triblock and the other is star asymmetric. For the sake of comparison, two polybutadiene (PB) homopolymer samples, having similar chain lengths of the PB blocks present in the S-B-S block copolymers, have been investigated. Dynamic mechanical measurements have been carried out for the real and imaginary parts of the complex shear modulus $\left(G^{\prime}, G^{\prime \prime}\right)$ in the temperature and frequency ranges from -110 to $30^{\circ} \mathrm{C}$ and from $10^{-2}$ to $15.9 \mathrm{~Hz}$, respectively. Complete master curves have been constructed for all samples investigated. Moreover, broadband dielectric spectroscopy has been carried out to cover wide temperature and frequency windows, -120 to $0^{\circ} \mathrm{C}$ and $10^{-1}$ to $10^{7} \mathrm{~Hz}$, respectively. The results showed that the molecular dynamics of the glass relaxation process of the PB or statistical PSB soft
\end{abstract}

Paper presented 3rd Annual European Rheology Conference (AERC 2006) April 27-29, 2006, Crete, Greece.

S. Z. Mohammady

Department of Chemistry, Faculty of Science, Cairo University, P.O.12613, Giza, Egypt

Present address:

S. Z. Mohammady $(\square)$

Department of Physical Chemistry, Basel University,

Klingelbergstr. 80,

4056 Basel, Switzerland

e-mail: sayed-zaki.mohammady@stud.unibas.ch phases in the block copolymers is dramatically changed when compared to the PB homopolymer. In addition, the molecular architecture is found to be an important factor in determining the molecular mobility of the soft blocks. The results are discussed in terms of the applied confinement of the counter PS hard phase, block lengths, domain thicknesses and the type of end-to-end junctions between the different polymeric blocks.

Keywords Dynamic mechanical and dielectric relaxations . Linear and star asymmetric block copolymers .

Glass relaxation process $\cdot$ Confinement

\section{Introduction}

Block copolymers demonstrate a number of unique properties as a result of their microphase separation (Pakula and Floudas 2000; Hadjichristidis et al. 2003; Allen and Bevington 1989). The resulting dimensions of microphases can vary between 5 and $500 \mathrm{~nm}$, which can be controlled at the synthesis level (Floudas et al. 1999). These microphases often develop highly organised domain morphologies (Pakula and Floudas 2000; Hadjichristidis et al. 2003; Allen and Bevington 1989; Floudas et al. 1999; Hueckstaedt et al. 2000; Xu and Lin 1996; Horak et al. 1996). These unique structures of block copolymers lead to a wide range of applications. Block copolymers can be used as engineering materials (Pakula and Floudas 2000; Hadjichristidis et al. 2003) or as compatibilisers (Xu and Lin 1996; Horak et al. 1996) for incompatible polymer blends. It has been suggested that block copolymers could be used in the development of new electronic devices (Morkved et al. 1994), the synthesis of mesoporous solids (Archibald and Mann 1993; Kresge et al. 1992), and in the fabrication of nanofibers (Liu 1997). Block copolymers exhibit periodic 
nanostructures due to immiscibility between the incompatible ( $A$ and $B$ ) sequences (Bates and Fredrickson 1999). Classical block copolymer microdomain morphologies include spheres of $A(B)$ on a body-centred cubic lattice in a $B(A)$ matrix, cylinders of $A(B)$ on a hexagonal lattice in a $B(A)$ matrix and co-alternating lamellae. In the past two decades, several complex (bicontinuous) nanostructures like the perforated lamellar, gyroid $(\mathrm{G})$ and double-diamond (D) morphologies have received considerable interest (Hajduk et al. 1994, 1998; Wohlgemuth et al. 2001). These nanostructures may develop if the copolymer composition falls within a narrow range between the cylindrical and lamellar morphologies.

Significant effort has been invested over the past decades to investigate the morphologies of a variety of block copolymers by means of several techniques [transmission electron microscopy (TEM), atomic force microscopy, small angle X-ray scattering] as a function of numerous parameters (composition, molecular weight, molecular architecture, method of preparation, annealing time and annealing temperature, contact media, blending). These investigations have been summarised in several review articles (Hadjichristidis et al. 2003; Allen and Bevington 1989). One key finding is that when block copolymers like styrene-butadiene-styrene (S-B-S) are heated above the upper glass-transition temperature $\left(T_{\mathrm{g}}\right)$, the microstructure of the polymer will vanish, and a homogeneous phase will form. The critical temperature is called the order-disorder transition (ODT) temperature. The rheological behaviour of block copolymers near their ODT has been reported extensively by many authors over the past three decades (Bates 1984; Rosedale and Bates 1990; Wu et al. 2004; Ryan et al. 1992).

The morphology and microphase separation of block copolymers with nonlinear architectures, such as a star block and graft copolymers, have been the focus of a considerable amount of recent work (Adhikari et al. 2003, 2005; Geiger et al. 2002; Knoll and Niessner 1998; Huy et al. 2003). These nonlinear architectures have been demonstrated to allow the control of morphologies independent of the familiar composition window that works in the case of linear diblock and triblock copolymers.

Based on the above, most of the previous investigations in the field of block copolymers are mainly concerned with the dependence of their morphology on several factors, as mentioned above. In contrast, the molecular dynamics of the glass relaxation processes of the different phases as well as other possible relaxation processes in block copolymers have been less investigated. Dynamic mechanical and differential scanning calorimetric experiments show that the glass transition in such systems is smeared out and spread over wide temperature range (Knoll and Niessner 1996, 1998; Nakajima 1996; Sierra et al. 1997; Tse 1989), especially when the volume fraction of one of the phases is less than one third. As a result, glass relaxation processes in such block copolymers are difficult to determine.

The objective of the present paper was to determine the impact of molecular architecture on the molecular dynamics of the glass relaxation processes of soft blocks in different types of block copolymers. To this aim, broadband dielectric spectroscopy and dynamic mechanical measurements in wide temperature and frequency ranges have been performed. Four candidates of block copolymers were chosen for this study. Two are S-B-S and S-SB-S linear triblock copolymer. Another two S-B-S and S-SB-S are star asymmetric. The styrene content in all the investigated samples is similar (about $74 \mathrm{wt} \%$ in each). Polybutadiene (PB) samples with similar chain lengths in block copolymers are also examined and compared with those PB soft phase in block copolymers.

In addition, TEM measurements are achieved to correlate the morphology as well as the domain sizes of the different phases (microscopic properties) with the macroscopic properties of the samples (dielectric and dynamic mechanical spectroscopic).

\section{Experimental part}

\section{Materials}

The block copolymers tested in this work were kindly supplied by Dr. K. Knoll, BASF, Ludwigshafen, Germany. Block copolymers were synthesised by butyl- and lithiuminitiated living anionic polymerisation. The star asymmetric block copolymer molecules (either S-B-S or S-SB-S) have approximately four asymmetric arms with a polystyrene core. Each arm is considered a linear asymmetric triblock copolymer, and one of these arms is much longer than the others (possesses a long PS tail). The PB block lengths (in the star asymmetric S-B-S) are uniform and have a number average molecular weight value of $\sim 6.0 \mathrm{~kg} / \mathrm{mol}$. Conversely, the SB soft blocks in S-SB-S are statistically random chains of styrene and butadiene units in equimolar ratio. The lengths of the SB blocks in the star asymmetric block copolymer are similar $(\sim 13.8 \mathrm{~kg} / \mathrm{mol})$. More information about the synthesis and the structure of materials is available elsewhere (Geiger et al. 2002; Knoll and Niessner 1996, 1998). A detailed description of the investigated block copolymers and homopolymers is given in Table 1 .

Sample preparation

\section{Dynamic mechanical measurements}

Homopolymers and copolymers sheets of $\sim 1.0-\mathrm{mm}$ thickness were prepared by compression molding at $180{ }^{\circ} \mathrm{C}$ 
Table 1 Chemical composition and physical characterization of the investigated block copolymers and homopolymers

\begin{tabular}{|c|c|c|c|c|c|c|c|c|c|}
\hline \multirow{2}{*}{$\begin{array}{l}\text { Material } \\
\text { name }\end{array}$} & \multirow{2}{*}{$\begin{array}{l}\text { Styrene block } \\
\text { content (wt } \%)\end{array}$} & \multirow[t]{2}{*}{ Soft block } & \multirow{2}{*}{$\begin{array}{l}\text { 1,2-vinyl } \\
\text { fraction }^{\mathrm{d}}\end{array}$} & \multicolumn{2}{|l|}{$T_{\mathrm{g}}^{\mathrm{e} /{ }^{\circ} \mathrm{C}}$} & \multirow{2}{*}{$\begin{array}{l}M_{\mathrm{n}} \text { PS block } \\
(\mathrm{kg} / \mathrm{mol})\end{array}$} & \multirow{2}{*}{$\begin{array}{l}M_{\mathrm{n}}(\mathrm{soft} \text { block}) \\
(\mathrm{kg} / \mathrm{mol})\end{array}$} & \multirow{2}{*}{$\begin{array}{l}\text { Total } M_{\mathrm{n}} \\
(\mathrm{kg} / \mathrm{mol})\end{array}$} & \multirow{2}{*}{$\begin{array}{l}\mathrm{PD}^{\mathrm{a}}= \\
M_{\mathrm{w}} / M_{\mathrm{n}}\end{array}$} \\
\hline & & & & $\begin{array}{l}\text { Soft } \\
\text { block }\end{array}$ & $\begin{array}{l}\text { Hard } \\
\text { block }\end{array}$ & & & & \\
\hline $\begin{array}{l}\text { S-B-S } \\
\text { KR2691 }\end{array}$ & 74.0 & Butadiene & 0.088 & -98.5 & 92.0 & 28.9 & 20.3 & 78.0 & 1.11 \\
\hline $\begin{array}{r}\text { S-B-S } \\
693 D\end{array}$ & 74.0 & Butadiene & 0.086 & -85.5 & 95.5 & - & 6.0 & 92.0 & 1.58 \\
\hline $\begin{array}{l}\text { S-SB-S }{ }^{b} \\
\text { BX6205 }\end{array}$ & 48 & $\begin{array}{l}\text { Styrene-- } \\
\text { butadiene } \\
(1: 1)\end{array}$ & 0.092 & -54.5 & 93.0 & 22.6 & 48.9 & 94.0 & 1.36 \\
\hline $\begin{array}{l}\text { S-SB-S } \\
\text { BX } \\
6230\end{array}$ & 48 & $\begin{array}{l}\text { Styrene-- } \\
\text { butadiene } \\
(1: 1)\end{array}$ & 0.091 & -62.5 & 95.0 & - & 13.8 & 106.0 & 1.70 \\
\hline PB & & & 0.070 & -99.7 & & - & - & 6.2 & 1.04 \\
\hline PB & & & 0.071 & -100.0 & & - & - & 21.0 & 1.04 \\
\hline
\end{tabular}

a Polydispersity index

${ }^{\mathrm{b}}$ Linear symmetric triblock copolymer

${ }^{\mathrm{c}}$ Star asymmetric block copolymer

${ }^{\mathrm{d}}$ Determined from ${ }^{13} \mathrm{C}$ NMR and ${ }^{1} \mathrm{H}$ NMR spectroscopies

${ }^{\mathrm{e}}$ Determined from the second heating scans using DSC at heating rate of $10 \mathrm{~K} / \mathrm{min}$

under vacuum for $1 \mathrm{~h}$. Samples were then cut into rectangular strips of dimensions $40.0 \times 6.0 \times 1.0 \mathrm{~mm}^{3}$.

\section{Dielectric measurements}

The sample capacitor consisted of two parallel gold-coated brass plates with a diameter of $20 \mathrm{~mm}$ between which the sample was sandwiched. The plate distance of $0.1 \mathrm{~mm}$ was kept constant by small Teflon spacers. Samples were pressed directly between the two electrodes at $180{ }^{\circ} \mathrm{C}$.

\section{Transmission electron microscopy}

From the same sheet used for dynamic mechanical measurements, ultra thin sections $(\sim 50-70 \mathrm{~nm})$ were prepared for TEM measurements. Samples were cut under liquid nitrogen. Then, these ultra thin sections were positioned on a copper grid on which an osmium tetraoxide layer was applied by vapor deposition for $24 \mathrm{~h}$. The function of osmium tetraoxide is to get contrast between the different phases in the block copolymers. Unsaturated blocks (such as $\mathrm{PB}$ ) react with osmium tetraoxide and appear black, while unreacting blocks appear white.

\section{Methods}

\section{Dynamic mechanical spectroscopy}

Measurements have been performed on a Rheometrics dynamic mechanical spectrometer (model RMS 800). Isothermal measurements of the complex shear modulus
$\left(G^{*}=G^{\prime}-i G^{\prime \prime}\right)$ have been carried out in the frequency range 0.0159 to $15.9 \mathrm{~Hz}$. The temperature was varied from -110 to $30{ }^{\circ} \mathrm{C}$ (depending on the material investigated) at isothermal steps of 5 and $10{ }^{\circ} \mathrm{C} / \mathrm{min}$, depending on the velocity of the process under consideration. The sample temperature was controlled with nitrogen gas. A resolution of $0.1{ }^{\circ} \mathrm{C}$ in temperature was achieved, and that of the loss factor $\left(\tan \delta=G^{\prime \prime} / G^{\prime}\right.$ ) was better than $10^{-2}$. At each isothermal step, strain sweep experiments of the complex shear modulus were carried out at two different frequencies $(1.0$ and $10 \mathrm{~Hz}$ ) to identify the linear viscoelastic range.

\section{Dielectric spectroscopy}

Dielectric measurements were carried out to cover a broad frequency range from $10^{-1}$ to $10^{7} \mathrm{~Hz}$. Isothermal frequency scans were performed in the temperature range from -120 to $0{ }^{\circ} \mathrm{C}$. A broadband dielectric spectrometer Novocontrol BDS 4,000 (based on the high-resolution ALPHA analyzer) was used to measure the dielectric function $\varepsilon^{*}(\nu)=\varepsilon^{\prime}(\omega)-$ $i \varepsilon^{\prime}(\nu)$ at 10 points per frequency decade in a frequency range of $10^{-1}-10^{7} \mathrm{~Hz}$.

TEM type EM 301 from Philips was used. The magnification factor applied is 100,000.

\section{Results and discussion}

Figure 1a (I) depicts the isothermal frequency scan measurements of the real and imaginary parts of the complex shear modulus $\left(G^{*}=G^{\prime}-i G^{\prime \prime}\right)$ for a PB homopol- 
ymer sample having number average molecular weight of $21.0 \mathrm{~kg} / \mathrm{mol}$ in the temperature range from -110 to $-40{ }^{\circ} \mathrm{C}$. Within the examined temperature and frequency ranges, two relaxation processes are detected. To compare the relaxation spectra of homopolymers and those behaviours in block copolymers, master curves are then constructed. Using the well-known time-temperature superposition principle (tTS) (Ferry 1980; Eisele 1990) where an arbitrary reference temperature is selected (referred to an isothermal step including the relaxation frequency of the maximum of a1

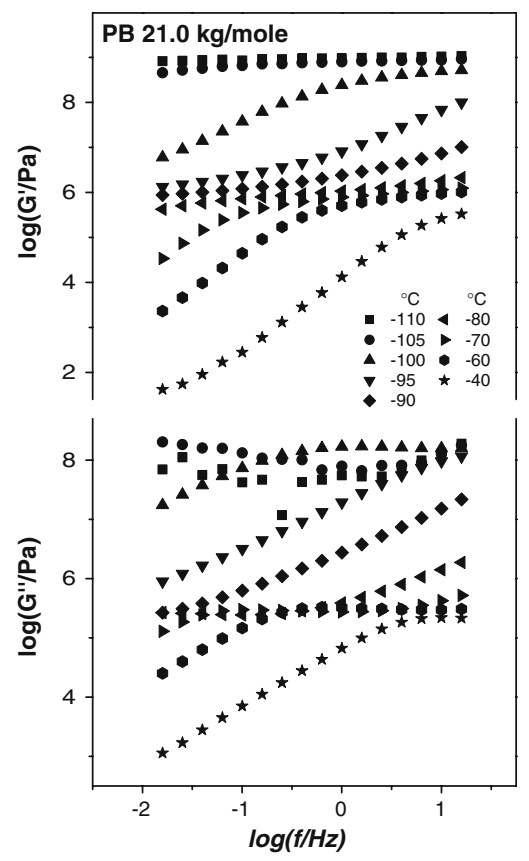

a4

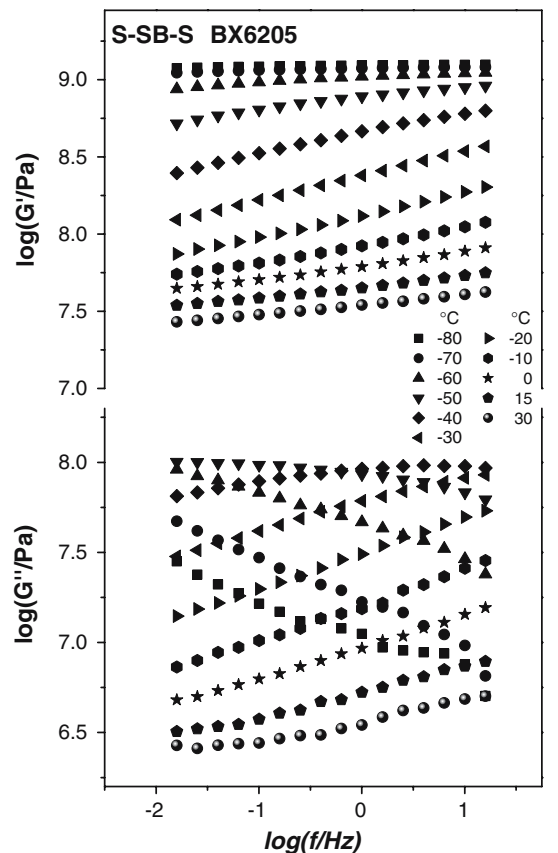

a2

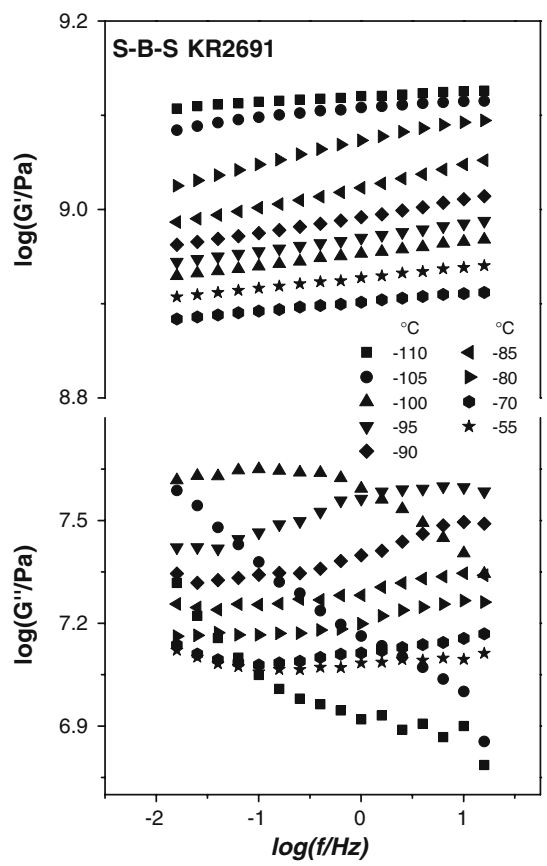

a5

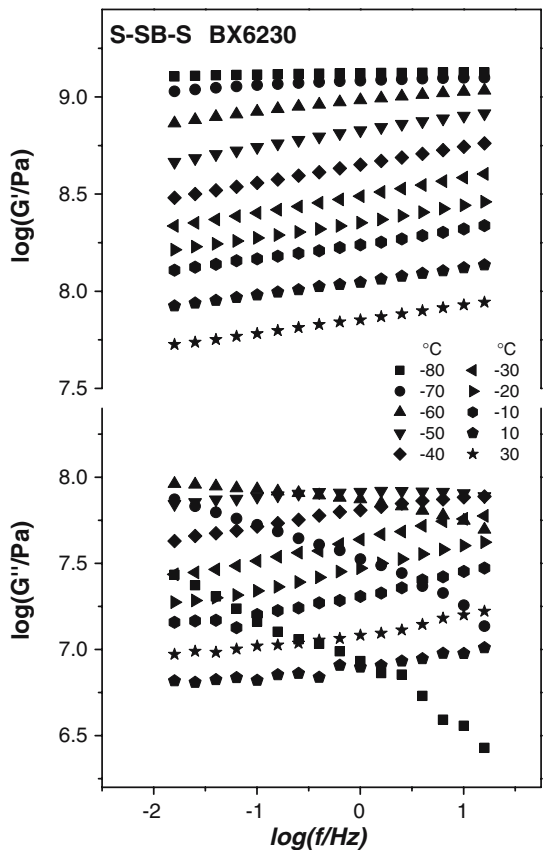

a3

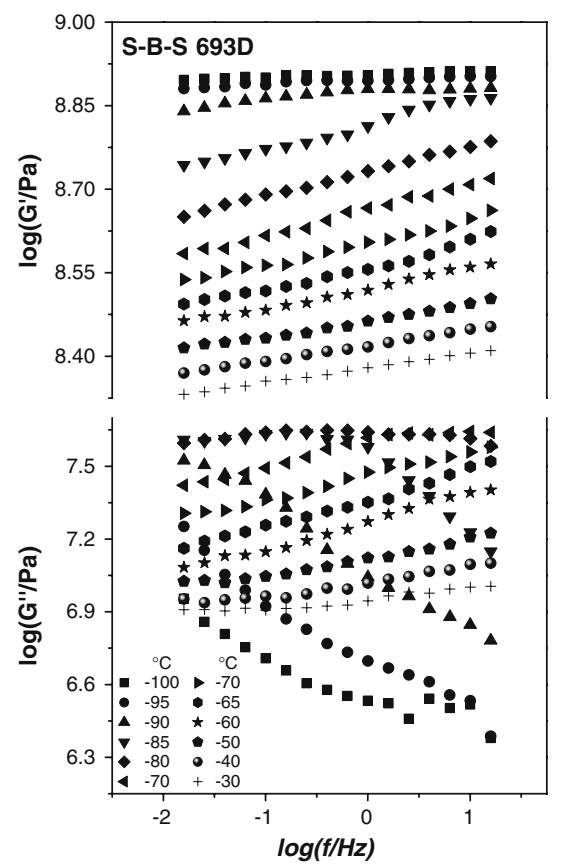

Fig. 1 a $(I-V)$ Isothermal measurements of the real and imaginary parts of the complex shear modulus of $\mathrm{PB}$ homopolymer sample (21.0 kg/mol), S-B-S KR 2691, S-B-S 693D, S-SB-S BX6205 and SSB-S BX6230 block copolymers, respectively. b Shift factors against temperature for PB homopolymer sample $(21.0 \mathrm{~kg} / \mathrm{mol})$, S-B-S KR 2691, S-B-S 693D, S-SB-S BX6205 and S-SB-S BX6230 block copolymers. c Shear modulus master curves of the PB homopolymer samples $(6.2$ and $21.0 \mathrm{~kg} / \mathrm{mol})$ reduced at $-100{ }^{\circ} \mathrm{C}$ 
b

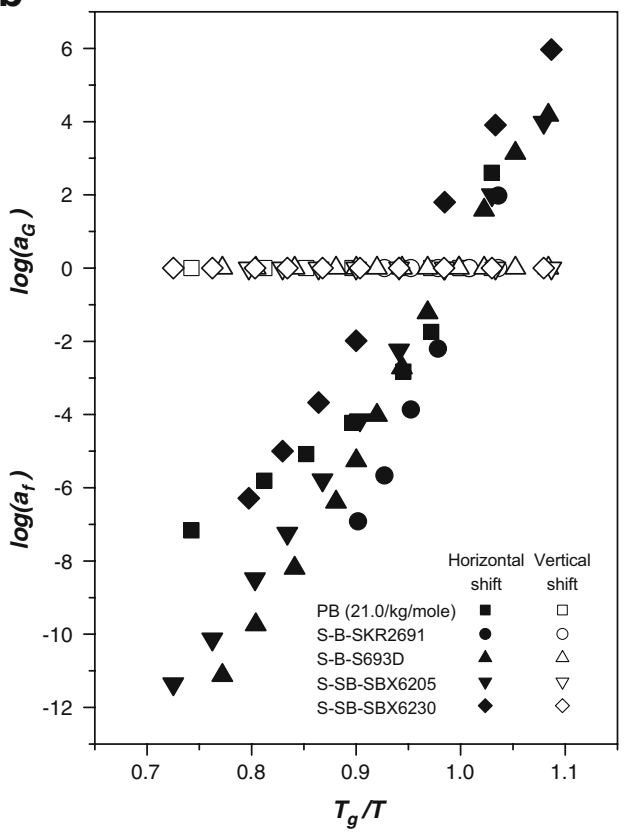

C

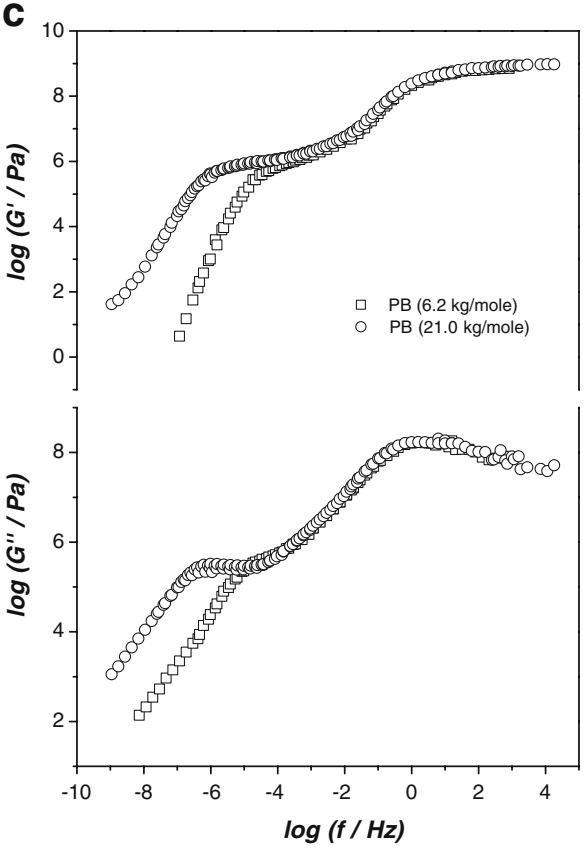

Fig. 1 (continued)

the process under consideration). Then, higher and lower temperature isotherms are shifted on the frequency axis to achieve the best superposition (Ferry 1980; Eisele 1990). Figure $1 \mathrm{~b}$ shows the frequency shift factors (horizontal shifts) and the vertical shift factors as a function of temperature. It is clear in Fig. $1 \mathrm{~b}$ that almost no vertical shifts have been applied, indicating the reliability of the constructed master curves. The absence of vertical shifts could be attributed to the narrow frequency range used where some vertical shifts might be expected to take place at lower frequencies than those involved here.

The relaxation spectra of the imaginary part in Fig. 1c reveal two relaxation processes. The first process appearing at higher frequencies around $\log f_{\max } \sim 0$ is attributed to the glass relaxation process of the PB homopolymers. This process is characterised also by a dramatic drop in the log $G^{\prime}$ values (about three orders of magnitudes). The low frequency relaxation process (see Fig. 1c) is attributed to the entanglement coupling resulting from the locus adherence, local kinks or long range contour loops between polymer chains (Ferry 1980; Eisele 1990). The appearance of this process is taken as direct evidence that the molecular weight of the investigated sample is much higher than the value of critical molecular weight of the polymer. In addition, for such relaxation spectra, it is found that the higher the molecular weight, the more extended the plateau modulus, which is in accordance with the results in Fig. 1c.

Figure $2 \mathrm{a}$ shows the temperature dependence of the dielectric loss $\left(\varepsilon^{\prime \prime}\right)$ over the frequency for the PB homopol- ymer sample $(21.0 \mathrm{~kg} / \mathrm{mol})$. Isothermal scans in the temperature range from -120 to $-100{ }^{\circ} \mathrm{C}$ reveal the secondary $(\beta)$ local relaxation process of the $\mathrm{PB}$ sample which can be characterised by its low activation energy (the values of $\log f_{\max }$ increase rapidly with increasing the temperature). The $\alpha$ glass relaxation process starts to contribute to the relaxation spectra above $-95{ }^{\circ} \mathrm{C}$. The rheological and dielectric properties of $\mathrm{PB}$ samples are consistent with previous findings (Zorn et al. 1995, 1997; Hofmann et al. 1996). In addition, Roland and Ngai (1991) and Zorn et al. (1995) have found that the shift factors of the glassy and terminal regimes, as obtained from dielectric measurements, are generally not the same. They have mentioned that the terminal range of PB $(21 \mathrm{~kg} / \mathrm{mol}, 7 \%$ vinyl content) starts at $-59.6{ }^{\circ} \mathrm{C}$ and continues at higher temperatures. This provides a tentative explanation for the deviation of the shift factors of the PB samples (Fig. 2c) above $-60{ }^{\circ} \mathrm{C}$. As the glassy regime is the range of current interest, shift factors of $\mathrm{PB}$ homopolymers above $-60{ }^{\circ} \mathrm{C}$ will not be included when comparing the activation behaviour of the glass process of $\mathrm{PB}$ homopolymers and PB phase in block copolymers.

Using the nonlinear least-square Levenberg-Marquard method (Havriliak and Negami 1967), the relaxation processes were fitted by a superposition of two HavriliakNegami $(\mathrm{HN})$ functions $(k=2)$ :

$\varepsilon^{*}(\omega)=\varepsilon_{\infty}+\sum_{k} \frac{\Delta \varepsilon_{k}}{\left(1+\left(i \omega \tau_{k}\right)^{\alpha_{k}}\right)^{\gamma_{k}}}$ 


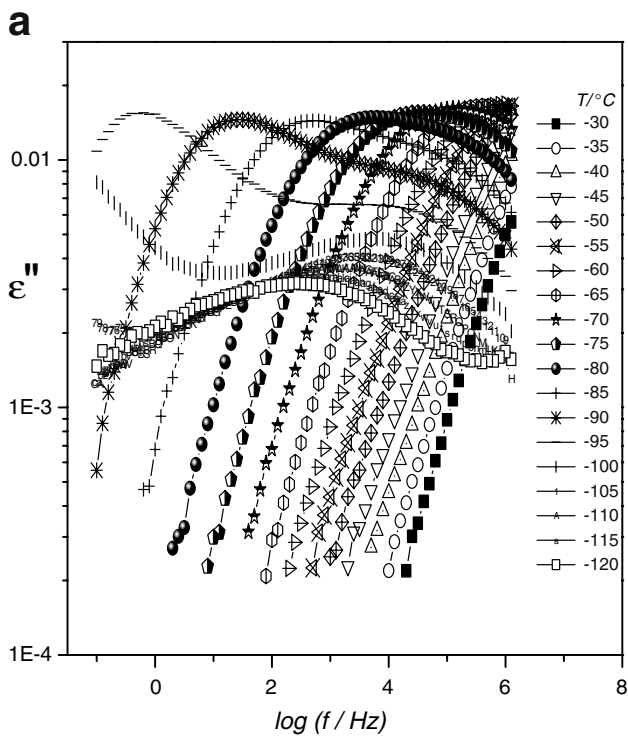

b

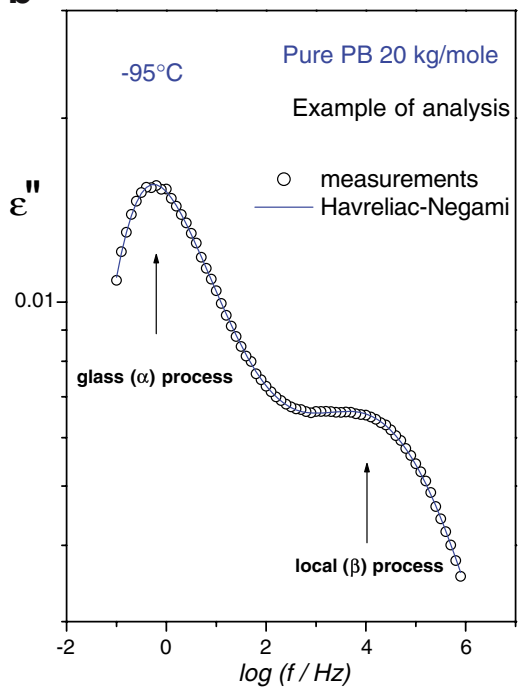

C

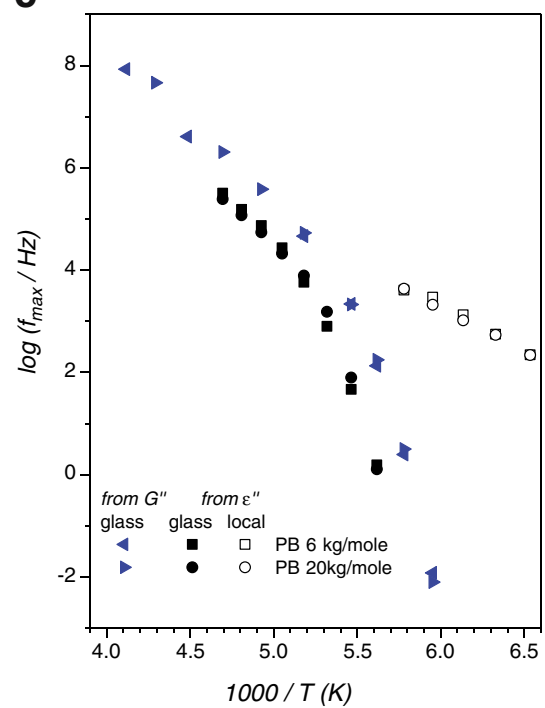

Fig. 2 a Isothermal measurements of the dielectric loss of $P B$ homopolymer sample $(21.0 \mathrm{~kg} / \mathrm{mol})$ at different temperatures. b An example of the analysis of the dielectric loss of PB homopolymer

sample $(21.0 \mathrm{~kg} / \mathrm{mol})$ by means of Eq. 1 (at $\left.-95{ }^{\circ} \mathrm{C}\right)$. c Activation curves evaluated for PB homopolymer samples $(6.2$ and $21.0 \mathrm{~kg} / \mathrm{mol})$ both from dynamic mechanical and dielectric measurements

with $\omega=2 \pi f, \varepsilon_{\infty}$ being the high frequency limit of $\varepsilon^{\prime}(\omega)$ outside the dispersion zone, $\Delta \varepsilon$ the intensities of each process and $0<\alpha \leq 1,0<\gamma \leq 1$. The maximum loss frequency $\omega_{\max }$ for each process is given by (Kahle et al. 1999):

$\omega_{\max }=\frac{1}{\tau}\left(\frac{\sin [\pi \alpha / 2]}{\tan [\pi \alpha / 2(\gamma+1)]}-\cos [\pi \alpha / 2]\right)^{-1 / \alpha}$

For $\omega<<\omega_{\max }$ and $\omega>>\omega_{\max }$ the HN function for $\varepsilon^{\prime \prime}(\omega)$ reduces to a power law with the exponent $\alpha$ and $\alpha \gamma$, respectively. To fit the $\alpha$ process, all parameters were left free, whilst for the intermediate and fast secondary or $\beta$ process, the asymmetry parameter $\gamma$ was set to 1 (corresponds to a symmetric peak which is typical for the $\beta$ process). A representative example of the analysis is given in Fig. $2 b$ where the circles represent the measured values, and the solid curve passing through the experimental points is the summation of these two relaxation processes. The evaluated values of $\log f_{\max }$ of the PB homopolymer samples $(6.2$ and $21.0 \mathrm{~kg} / \mathrm{mol})$ are depicted in Fig. 2c. It can be observed that the activation curves for the glass relaxation process in both samples are almost identical (typical behaviour above the critical molecular weight), regardless if they are determined mechanically or dielectrically. Moreover, the activation curves of the glass process evaluated from $G^{\prime \prime}$ and $\varepsilon^{\prime \prime}$ are parallel to each other. This result is in good agreement with literature data (Heinrich and Stoll 1988; Weyer et al. 1997; Mohammady et al. 2001, 2002). For this reason, it is possible to carry out vertical shifts of the activation curves to be exactly superimposed on a single common activation curve to increase both the number of data points and the width of the frequency covered decades. This will be done in this work when it is possible to evaluate the activation curves mechanically and dielectrically.

Isothermal frequency scans of the complex shear modulus for S-B-S KR2691, S-B-S 693D samples have been carried out in the temperature range from -110 to $-30{ }^{\circ} \mathrm{C}$ to construct the master curves (reduced at $-100{ }^{\circ} \mathrm{C}$ ) which are shown in Fig. 3a. The results indicate the following:

1- $\log f_{\max }$ values of the glass process of the PB phase in the block copolymers is lower than that of pure PB. The values are $0.5,-0.7$ and -5.5 for pure $\mathrm{PB}, \mathrm{S}-\mathrm{B}-\mathrm{S}$ KR2691 and S-B-S 693D, respectively (Fig. 3a, b). It is worthwhile to mention here that the molecular dynamics of the local $\beta$ process of the PB phase in the block copolymers are faster than that observed in $\mathrm{PB}$ homopolymer (Fig. 3b). A difference of about one decade is observed in the S-B-S KR2691 sample. This may be attributed to some sort of defects within the PB blocks due to the incorporation of the PS end blocks in the PB domains.

2- A broadening of the $G^{\prime \prime}$ spectra of the block copolymers is observed as compared to that of pure PB. The full width at the half maximum (FWHM) of the different samples, as a mean to quantify the width of the relaxation spectra, are $\sim 3.2$ and $\sim 5.9$ decades for homopolymer and block copolymers (Fig. 3c).

3- The maximum value of the $G^{\prime \prime}$ spectra is much lower in block copolymers than in pure PB. This can be attributed to the high fraction of PS hard phase in the 
a

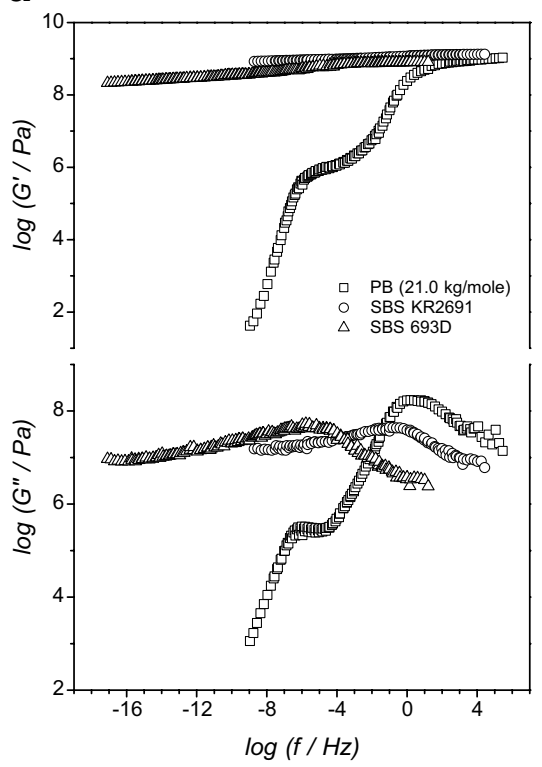

b

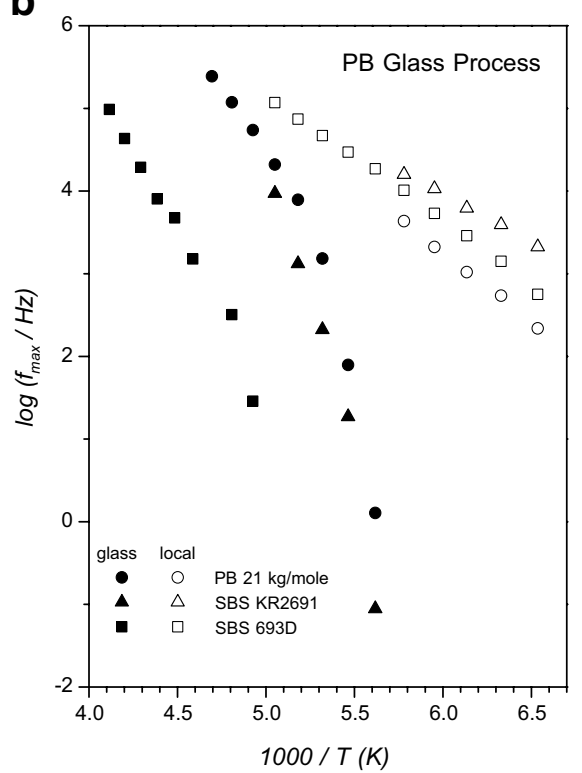

c

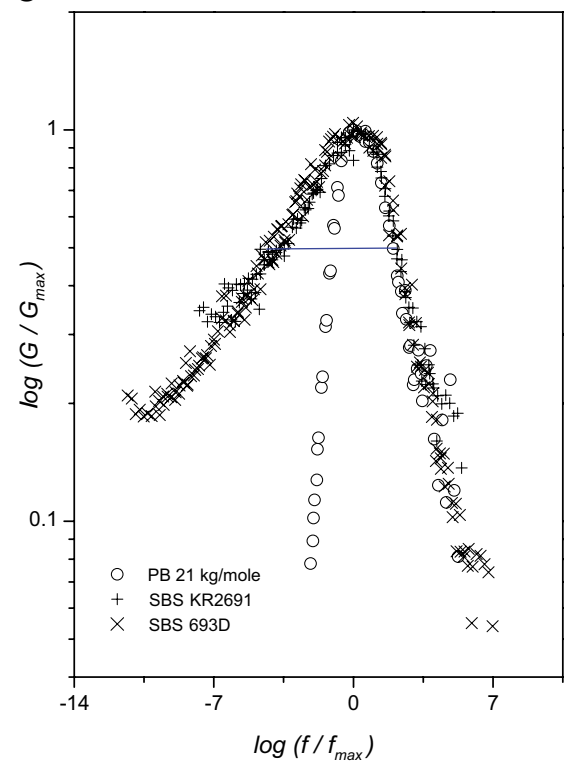

Fig. 3 a Shear modulus master curves of the PB homopolymer samples (21.0 kg/mol), S-B-S KR 2691 and S-B-S 693D block copolymer samples reduced at $-100{ }^{\circ} \mathrm{C}$. b Activation curves evaluated for $\mathrm{PB}$ homopolymer samples $(6.2$ and $21.0 \mathrm{~kg} / \mathrm{mol})$, S-B-S KR 2691 and S-B-
S 693D block copolymer samples both from dynamic mechanical and dielectric measurements. c Normalized plot of the loss modulus as a function of frequency for PB homopolymer samples $(21.0 \mathrm{~kg} / \mathrm{mol})$, S-B-S KR 2691 and S-B-S 693D block copolymer samples block copolymers. The hard polystyrene domains act as reinforcing filler and as physical cross-links that constrain the rubbery matrix.

4- The plateau modulus of the linear S-B-S KR2691 copolymer is $\sim 3.8$ times higher than that in the star asymmetric S-B-S 693 D block copolymer. This pronounced difference in the plateau modulus values can be attributed to the difference in morphology in both block copolymers (Fig. 4a, b).

It would be of interest here to recall the literature data reported in the field of confinement and size effects on the glass transition temperature. Significant effort has been made to investigate the glass transition temperature in confined geometries both for small molecules confined in nanopores (Alcoutlabi and McKenna 2005; Wendt and Richert 1999; Wang et al. 2004; He et al. 2005; Jackson and McKenna 1991; Zhang et al. 1992) and ultra thin polymer films (Alcoutlabi and McKenna 2005; Jain and de Pablo 2002; Dalnoki-Veress et al. 2000, 2001; Roth and Dutcher 2004). Deviation from the bulk properties was observed. It is surprising to find that confinement may increase, decrease or not affect the glass transition temperature. Existing theories of glass transition are still unable to explain the range of behaviour observed at the nano-sized scale. This may be attributed to the fact that the glass transition phenomenon itself is not completely understood.

Block copolymers of different microdomain morphologies could be considered as finite confined systems depending on their morphology. For instance, block copolymers exhibiting cylindrical microdomain morphology may be considered as systems confined in nanopores (Alcoutlabi and McKenna 2005; Wendt and Richert 1999; Wang et al. 2004; He et al. 2005; Jackson and McKenna 1991; Zhang et al. 1992). However, block copolymers exhibiting lamellar microdomain morphology may be considered as systems possessing thin film confinement (Mohammady et al. 2001, 2002; Mansour et al. 2003). For small molecules confined in nanopores, the confinement is considered as hard confinement (i.e. an increase in the glass transition temperature, $T_{\mathrm{g}}$; Alcoutlabi and McKenna 2005; Wang et al. 2004; He et al. 2005; MacFarlane and Angell 1982), but for spheres or nanodroplets suspended in fluid environment, the confinement is considered to be soft (i.e. a reduction in the glass transition temperature, $T_{\mathrm{g}}$ ). The concept above can also be applied to the results obtained in Fig. $3 \mathrm{a}-\mathrm{c}$.

The PB cylindrical microdomains in S-B-S KR2691 block copolymer are effectively confined within nanopores of dimensions of $8.3 \mathrm{~nm}$ within the hard PS matrix (Fig. 4a). However, TEM results (Fig. 4b) show that the morphology of the S-B-S 693D sample does not fit into the common morphology scheme of block copolymers, as it reveals an irregular wormlike morphology. Styrene and butadiene form an interpenetrating network with styrene as the predominant phase. Large styrene worms $(24 \mathrm{~nm})$, small PS inclusions in PB (6 nm) and PB lamellae $(7.5 \mathrm{~nm})$ are observed (Knoll and Niessner 1996, 1998). The 


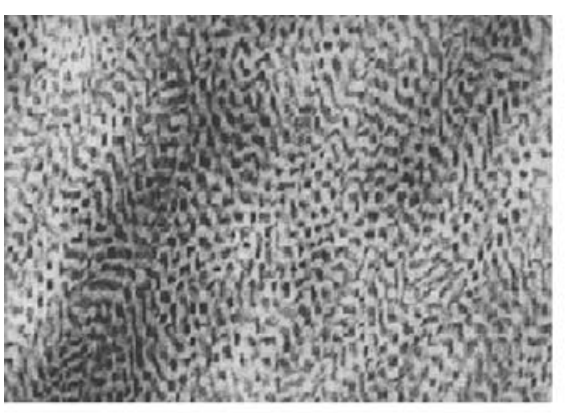

a S-B-S KR 2691

$100 \mathrm{~nm}$

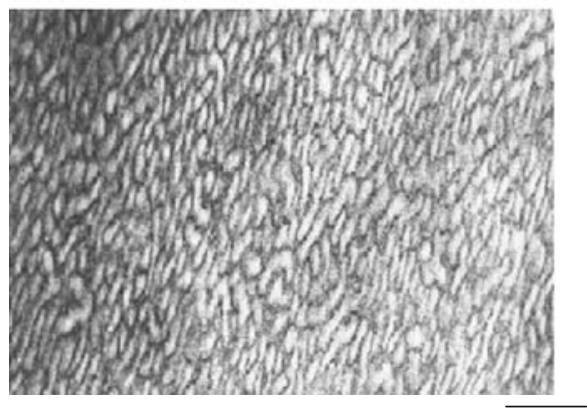

b S-B-S 693D

$100 \mathrm{~nm}$
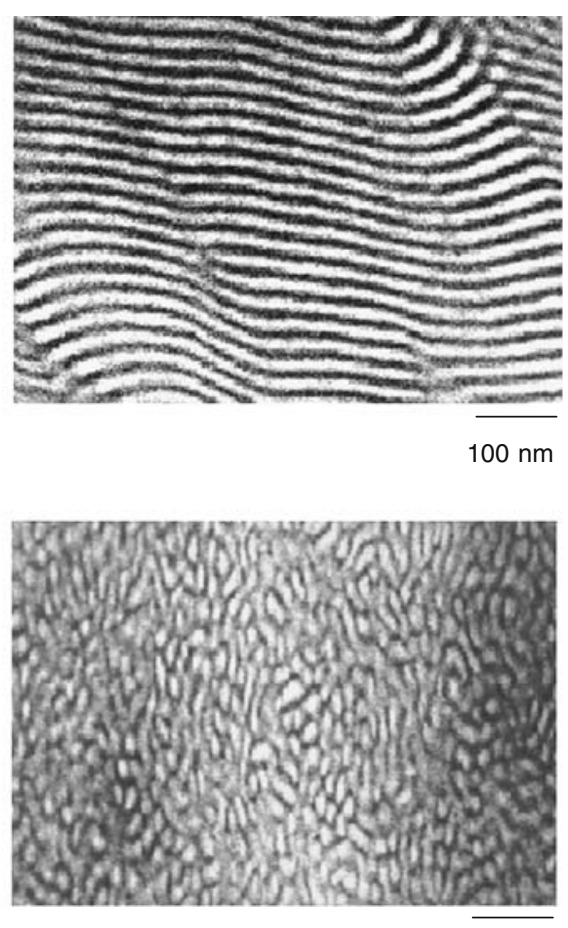

$100 \mathrm{~nm}$

d S-SB-S BX 6230

C S-SB-S BX 6205

$100 \mathrm{~nm}$

Fig. 4 TEM, of a S-B-S KR 2691 and S-B-S 693D block copolymer samples and b S-SB-S BX6230 block copolymer samples

distribution of the various domains in the block copolymers controls, to a great extent, the macroscopic mechanical properties of the samples. The reduction in the $\log f_{\max }$ values as well as the broadening of $G^{\prime \prime}$ spectra of block copolymers as compared to pure PB (Fig. 3a-c) can be attributed to constraint applied by the PS hard matrix confinement on the PB domains. However, the dramatic reduction in $\log f_{\max }$ values of the glass relaxation process in S-B-S 693D sample (about six orders of magnitude) is augmented further due to the difference in domain thicknesses of the PB phase in both block copolymers (Fig. 4a, b). The dramatic drop in the $\log f_{\max }$ values of the glass relaxation process of S-B-S 693D sample may be attributed to the increased number of network junctions between $\mathrm{PB}$ and PS domains which act as points of cross-links that enhance the restrictions on the molecular mobility of the PB phase in the sample. As S-B-S KR2691 is a linear triblock copolymer, the distance between 'cross-links' here is the same as the PB block length $(20.3 \mathrm{~kg} / \mathrm{mol}$; Table 1$)$. For comparison, the PB block length in S-B-S 693D is $6.0 \mathrm{~kg} /$ mol, such that the distance between two successive crosslinks in S-B-S $693 \mathrm{D}$ is $~ 3.5$ times shorter than in the linear S-B-S KR 2691 sample. This would be the most important factor that prohibits the molecular mobility of the PB phase in the asymmetric star block copolymer (Fig. 3ac) which is in good agreement with results observed by Ge et al. (2000) who reported that in case of constrained films, where there is a strong interaction between the polymer and the substrate, an increase in the $T_{\mathrm{g}}$ (or a reduction in $\log$ $\left.f_{\max }\right)$ with decreasing film thickness was observed for different polymers. In the current work, the number of network junctions between the PB phase and the PS matrix (acting as a substrate in our block copolymers) is greatest in the S-B-S 693D sample.

Figure 5a depicts the shear modulus master curves of the S-SB-S BX6205 and S-SB-S BX6230 copolymers reduced at $-50{ }^{\circ} \mathrm{C}$. The results, as shown in Fig. $5 \mathrm{a}$, indicate the following:

1- $\log f_{\max }$ values of the glass process of the SB phase in S-SB-S BX6205 (block copolymer having linear molecular architecture) is $\sim 2.1$ decades lower than that S-SB-S BX6230 (star asymmetric block copolymer). This behaviour is quite unlike that observed in the S-B$\mathrm{S}$ samples (Fig. 3a-c) where the value of the PB phase for S-B-S KR2691 (linear triblock copolymer) leads that of the corresponding PB phase in the star asymmetric one by $\sim 4.8$ decades.

2- The FWHM of the $G^{\prime \prime}$ spectra are very broad (7.3 and 6.9 in S-SB-S BX6230 and S-SB-S BX6205, respectively). The exhibited large FWHM values, compared to homopolymers (3.2 decades for PB; Fig. 3c), can be considered as a proof of the presence of an additional confinement of the PS phase (Alcoutlabi and McKenna 2005; Pissis et al. 1994). 
a

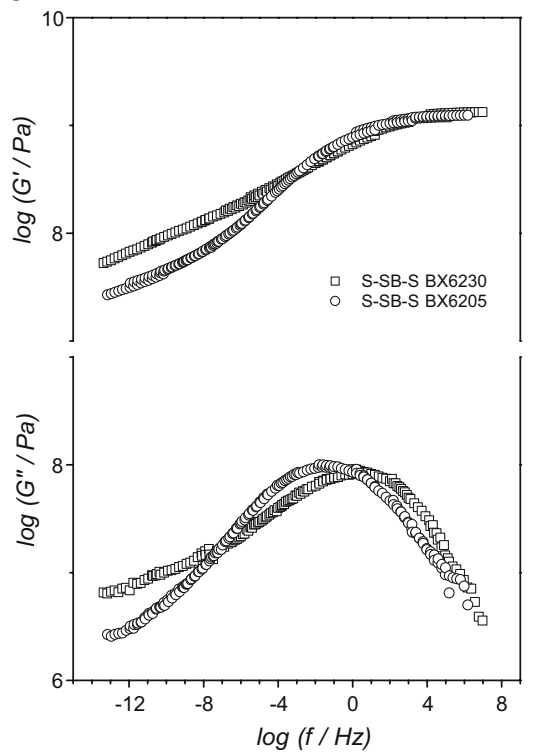

b

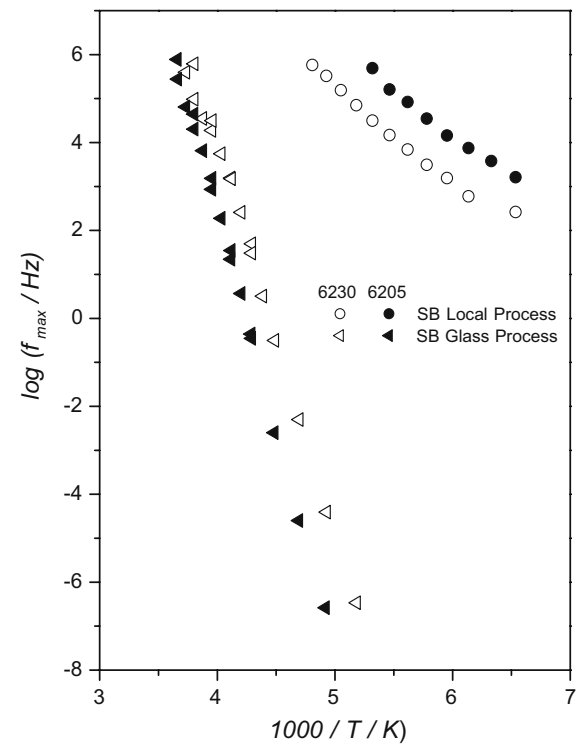

C

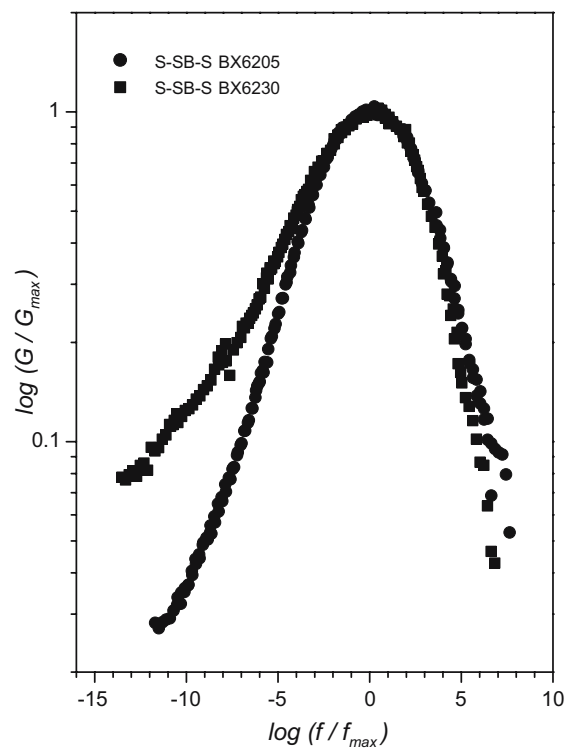

Fig. 5 a Shear modulus master curves of S-SB-S BX6205 and S-SB-S BX6230 block copolymer samples reduced at $-50^{\circ} \mathrm{C}$. b Activation curves evaluated for S-SB-S BX6205 and S-SB-S BX6230 block copolymer samples both from dynamic mechanical and dielectric measurements. c Normalized plot of the loss modulus as a function of frequency for S-SBS BX6205 and S-SB-S BX6230 block copolymer samples
3- The plateau modulus of the S-SB-S BX6230 sample is about two times higher than that observed for the SSB-S BX6205 sample.

The question now is why the molecular mobility of the glass process of the SB phase in S-SB-S BX6230 (star asymmetric block copolymer) is higher than in the S-SB-S BX6205 linear triblock copolymer? To answer this question, the following effects should be considered:

1- The nature of the S-SB junctions: We have mentioned previously that the PS-PB junctions can be considered as chemical 'cross-links' in S-B-S block copolymers, and their increase led to a great reduction in the molecular mobility of the soft PB phase. However, the situation is different when we consider the PS-SB junctions in S-SB-S block copolymers. The interaction between the PS and SB phase is significantly higher compared to the PS-PB system. This can increase the amount of the SB segments that are able to incorporate in the PS domains. This can be elucidated by the presence of the fuzzy borders of the PS and SB microdomains in the S-SB-S BX6230 sample (Fig. 4d) where less contrast is attained from TEM measurements (indicated by the presence of grey areas in Fig. 4d). This can be taken as a proof of the presence of an extended interface typical for a system near to the so-called 'order-disorder transition temperature, ODT' in block copolymers (Knoll and Niessner 1996, 1998; Mohammady et al. 2002). This extended interface will, in turn, reduce the hard character of the PS domains, leading to a reduction of the stiffness in the star asymmetric S-SB-S BX6230 block copolymers when compared to the linear one.

2- The number of end groups: The SB block length in SSB-S BX6230 is $~ 3.5$ times shorter than in S-SB-S BX6205 (Table 1). As the SB ends at the PS-SB junctions are still labile (proven by their ability to extend within the PS phase as shown in Fig. 4d), increasing their number would increase the molecular mobility of the SB phase in the sample (Fig. 5a, b).

3- The average domain thicknesses (Fig. 4c, d) of the SB phase in S-SB-S BX6230 and S-SB-S BX6205 are 7.5 and $10.1 \mathrm{~nm}$, respectively. The cooperative rearranging regions, CRR, which are responsible for the glass relaxation process in a series of random styrene butadiene rubber (SBR copolymers) covering a wide composition range, have been found to be in the order of 10-12 nm (Richter 1996; Mohammady et al. 2001, 2002). The average domain thickness of the SB domain in S-SB-S BX6230 (7.5 $\mathrm{nm})$ is lower than the CRR region in bulk SBR and still lower than that of the S-SBS BX6205 sample. This, in turn, would lead to an enhancement of the molecular mobility of the SB blocks in the star asymmetric block copolymer (Fig. 5a-c). 


\section{Conclusion}

The molecular dynamics of the relaxation processes of the soft blocks in different types of block copolymers having different molecular architectures have been investigated. Four model block copolymers were investigated, namely, two styrene-butadiene-styrene (S-B-S) block copolymers and two styrene-styrene butadiene-styrene (S-SB-S) where the soft blocks are PB homopolymer and statistical SB random copolymer (having styrene/butadiene molar ratio of $1: 1)$, respectively. Dynamic mechanical measurements were made and master curves constructed for temperature and frequency ranges from -110 to $30{ }^{\circ} \mathrm{C}$ and from $10^{-2}$ to $15.9 \mathrm{~Hz}$, respectively. Broadband dielectric spectroscopy was also carried out in the temperature and frequency windows from -120 to $0{ }^{\circ} \mathrm{C}$ and $10^{-1}$ to $10^{7} \mathrm{~Hz}$, respectively. The results show that the molecular dynamics of the glass process of the soft phase in block copolymers are dramatically changed as compared to the behaviour in the bulk. For instance, the relaxation frequency of the maxima ( $\log f_{\max }$ ) of the glass process of the PB in S-B-S KR2601 (linear triblock) and S-B-S 693D (star asymmetric) lags that in pure PB by 1.2 and 6.0 decades, respectively. On the other hand, the $\log f_{\max }$ value of the SB soft blocks in the star asymmetric S-SB-S BX6230 block copolymer is found to be $\sim 2.1$ decades faster than in the linear triblock candidate (S-SB-S BX6205). It is concluded that the molecular architecture plays an important role in determining the molecular mobility of the soft blocks. The results are explained in terms of the applied confinement of the counter blocks, block lengths, domain thicknesses and the type of end to end junctions between the different blocks.

Acknowledgement The author gratefully acknowledge the Deutscher Akademischer Austauschdienst (DAAD) and Max Plank Institute for Polymer research (MPIP) for the financial support provided. Many thanks are due to Dr. S. Khale for assistance in programming, data fitting and DETA measurements. I would like to thank Prof. Dr. A. Burbidge and Dr. J. Ubbink for their valuable suggestions during the revision of this work.

\section{References}

Adhikari R, Michler GH, Knoll K (2003) Morphology and micromechanical behaviour of styrene/butadiene block copolymers and their blends with polystyrene. Macromol Symp 198:117-134 (7th European Symposium on Polymer Blends, 2002)

Adhikari R, Buschnakowski M, Lebek W, Godehardt R, Michler GH, Calleja Balta FJ, Knoll K (2005) Asymmetric PS-block-(PS-coPB)-block-PS block copolymers: morphology and deformation behavior of star block copolymer/PS blends. Polym Adv Technol $16: 175-182$

Alcoutlabi M, McKenna GB (2005) Effects of confinement on material behavior at the nanometer size scale. J Phys Condens Matter 17:461-524
Allen G, Bevington JC (1989) Comprehensive polymer science: the synthesis, characterization, reactions and applications of polymers, vol 2. Polymer properties. Pergamon, Oxford

Archibald DD, Mann S (1993) Template mineralization of selfassembled anisotropic lipid microstructures. Nature 364:430 433

Bates FS (1984) Block copolymers near the microphase separation transition. 2. Linear dynamic mechanical properties. Macromolecules 17:2607-2613

Bates FS, Fredrickson GH (1999) Block copolymers: designer soft materials. Phys Today 52:32-38

Dalnoki-Veress K, Forrest JA, de Gennes PG, Dutcher JR (2000) Glass transition reductions in thin freely-standing polymer films: a scaling analysis of chain confinement effects. J de Physique IV: Proceedings 10 Pr7/221-Pr7/226 (Pr7, International Workshop on Dynamics in Confinement, 2000)

Dalnoki-Veress K, Forrest JA, Murray C, Gigault C, Dutcher JR (2001) Molecular weight dependence of reductions in the glass transition temperature of thin, freely standing polymer films. Phys Rev E 63:031801

Eisele U (1990) Instruction to polymer physics. Springer, Berlin

Ferry JD (1980) Viscoelastic properties of polymers, 3rd edn. Wiley, New York

Floudas G, Meramveliotaki K, Hadjichristidis N (1999) Segmental and chain dynamics of polyisoprene in block copolymer/ homopolymer blends. A dielectric spectroscopy study. Macromolecules 32:7496-7503

Ge S, Pu Y, Zhang W, Rafailovich M, Sokolov J, Buenviaje C, Buckmaster R, Overney RM (2000) Shear modulation force microscopy study of near surface glass transition temperatures. Phys Rev Lett 85:2340-2343

Geiger K, Knoll K, Langela M (2002) Microstructure and rheological properties of triblock copolymers under extrusion conditions. Rheol Acta 41:345-355

Hadjichristidis N, Pispas S, Floudas G (2003) Block copolymers synthetic strategies, physical properties, and applications. Wiley, New York

Hajduk A, Harper PE, Gruner SM, Honeker CC, Kim G, Thomas EL, Fetters LJ (1994) The gyroid: a new equilibrium morphology in weakly segregated diblock copolymers. Macromolecules 27:4063-4075

Hajduk A, Ho RM, Hillmyer MA, Bates FS, Almdal K (1998) Transition mechanisms for complex ordered phases in block copolymer melts. J Phys Chem B 102:1356-1363

Havriliak S, Negami S (1967) A complex plane representation of dielectric and mechanical relaxation processes in some polymers. Polymer 8:161-205

He F, Wang LM, Richert R (2005) Dynamics of supercooled liquids in the vicinity of soft and hard interfaces. Phys Rev B 71:144205.1144205.10

Heinrich W, Stoll B (1988) Description of the freezing-in process in poly(vinyl acetate) based on the meander model. Prog Colloid Polym Sci 78:37-53

Hofmann A, Algeria A, Colmenero J, Willner L, Buscaglia E, Hadjichristidis N (1996) Secondary and segmental relaxation in polybutadienes of varying microstructure: dielectric relaxation results. Macromolecules 29:129-134

Horak Z, Fort V, Hlavata D, Lednicky F, Vecerka F (1996) Compatibilization of high-impact polystyrene/polypropylene blends. Polymer 37:65-73

Hueckstaedt H, Goldacker T, Goepfert A, Abetz V (2000) Core-shell double gyroid morphologies in $\mathrm{ABC}$ triblock copolymers with different chain topologies. Macromolecules 33:3757-3761

Huy TA, Adhikari R, Michler GH (2003) Deformation behavior of styrene-block-butadiene-block-styrene triblock copolymers having different morphologies. Polymer 44:1247-1257 
Jackson CL, McKenna GB (1991) The glass transition of organic liquids confined to small pores. J Non Cryst Solids 131133:221-224

Jain TS, de Pablo JJ (2002) Monte Carlo simulation of freestanding polymer films near the glass transition temperature. Macromolecules 35:2167-2176

Kahle S, Schroter K, Hempel E, Donth E (1999) Calorimetric indications of a cooperativity onset in the crossover region of dynamic glass transition for benzoin isobutyl ether. J Chem Phys 111:6462-6470

Knoll K, Niessner N (1996) Application of anionic polymerization research: developed from a symposium sponsored by division of polymer chemistry: the 212th National Meeting Of The American Chemical Society, Orlando, Florida (August 25-29)

Knoll K, Niessner N (1998) Styrolux and styroflex. From transparent high impact polystyrene to new thermoplastic elastomers. Syntheses, applications, and blends with other styrene-based polymers, (International Symposium on Ionic Polymerization, 1997). Macromol Symp 132:231-243

Kresge CT, Leonowicz ME, Roth WJ, Vartuli JC, Beck JS (1992) Ordered mesoporous molecular sieves synthesized by a liquidcrystal template mechanism. Nature 359:710-712

Liu G (1997) Nanofibers. Adv Mater 9:437-439

MacFarlane DR, Angell CA (1982) An emulsion technique for the study of marginal glass formation in molecular liquids. J Phys Chem 86:1927-1930

Mansour AA, Mohamed MA, Minko S (2003) Effect of block position on the dynamics of the glass processes in carbonate/styrene triblock copolymers. J Elastomers Plast 35:277-294

Mohammady SZ, Mansour AA, Von Soden W (2001) Effect of crosslinking on block and random copolymers of styrene and butadiene. Macromol Chem Phys 202:2732-2741

Mohammady SZ, Mansour AA, Knoll K, Stoll B (2002) Detection of the glass relaxation process of the PS-phase in block copolymers. Polymer 43:2467-2478

Morkved TL, Wiltzius P, Jeager HM, Grier DG, Witten TA (1994) Mesoscopic self-assembly of gold islands on diblock-copolymer films. Appl Phys Lett 64:422-424

Nakajima N (1996) Viscoelastic behavior of styrene-butadienestyrene block copolymers in temperature range of glass-rubber transition of styrene block. Rubber Chem Technol 69:73-80

Pakula T, Floudas G (2000) Dynamics and viscoelastic effects in block copolymers: real and simulated systems, Marcel Dekker, New York

Pissis P, Daoukaki-Diamanti D, Apekis L, Christodoulides C (1994) The glass transition in confined liquids. J Phys Condens Matter 6 (21), L325-L328

Richter N (1996) Ph.D. thesis, Ulm University, Ulm, Germany
Roland CM, Ngai KL (1991) Segmental relaxation and molecular structure in polybutadienes and polyisoprene. Macromolecules 24:5315-5319

Rosedale JH, Bates FS (1990) Rheology of ordered and disordered symmetric poly(ethylenepropy1ene)-poly(ethylethylene) diblock copolymers. Macromolecules 23:2329-2338

Roth CB, Dutcher JR (2004) Mobility on different length scales in thin polymer films. In: Dutcher JR, Marangoni AG (eds) Soft materials: structure and dynamics. Dekker, New York

Ryan AJ, Macosko CW, Bras W (1992) Order-disorder transition in a block copolyurethane. Macromolecules 25:6277

Sierra CA, Galan C, Fatou JG, Parellada MD, Barrio JA (1997) Thermal and mechanical properties of poly(styrene-b-ethyleneco-butylene-b-styrene) triblock copolymers. Polymer 38:43254335

Tse MF (1989) Studies of triblock copolymer-tackifying resin interactions by viscoelasticity and adhesive performance. J Adhes Sci Technol 3:551-570

Wang LM, He F, Richert R (2004) Slow dynamics and the glass transition in confining systems. Mater Res Soc Symp Proc 790: P8.6.1-P8.6.12

Wendt H, Richert R (1999) Cooperativity and heterogeneity of the dynamics in nano-confined liquids. J Phys Condens Matter 11: A199-A206

Weyer S, Hensel A, Korus J, Donth E, Schick C (1997) Broad band heat capacity spectroscopy in the glass-transition region of polystyrene. Thermochim Acta 304/305:251-255

Wohlgemuth M, Yufa N, Hoffman J, Thomas EL (2001) Triply periodic bicontinuous cubic microdomain morphologies by symmetries. Macromolecules 34:6083-6089

Wu L, Cochran EW, Lodge TP, Bates FS (2004) Consequences of block number on the order-disorder transition and viscoelastic properties of linear $(\mathrm{AB}) n$ multiblock copolymers. Macromolecules 37:3360-3368

Xu G, Lin S (1996) Diblock copolymer compatibilizers for blends of isotactic polystyrene and isotactic polypropylene. Polymer $37: 421-427$

Zhang J, Liu G, Jonas J (1992) Effects of confinement on the glass transition temperature of molecular liquids. J Phys Chem 96:3478-3480

Zorn R, Mckenna GB, Willner L, Richter D (1995) Rheological investigation of polybutadienes having different microstructures over a large temperature range. Macromolecules 28:8552-8562

Zorn R, Mopsik FI, Mckenna GB, Willner L, Richter D (1997) Dynamics of polybutadienes with different microstructures. 2 . Dielectric response and comparisons with rheological behavior. J Chem Phys 107:3645-3655 